\title{
DETERMINAÇÃO DE MAGNITUDE DE CORRIDAS DE DETRITOS EM CARAGUATATUBA/SP: AVALIAÇÃO DE METODOLOGIA
}

\author{
Vivian Cristina Dias $^{(\mathrm{a})}$, Bianca Carvalho Vieira ${ }^{(\mathrm{b})}$, Marcelo Fischer Gramani ${ }^{(\mathrm{c})}$ \\ (a) Departamento de Geografia, Universidade de São Paulo, vivian.cristina.dias@usp.br \\ (b) Departamento de Geografia/Universidade de São Paulo, biancacv@usp.br \\ (c) Instituto de Pesquisas Tecnológicas (IPT), mgramani@ipt.br
}

\section{Eixo: GEOGRAFIA FÍSICA E DESASTRES NATURAIS}

\begin{abstract}
Resumo
Este artigo tem como objetivo a determinação da magnitude de corridas de detritos em bacias hidrográficas em Caraguatatuba/SP a partir da aplicação e avaliação da metodologia de classificação de magnitude a partir da área inundada $\left(\mathrm{m}^{2}\right)$. Para tal, os seguintes procedimentos metodológicos foram feitos: a) seleção de bacias hidrográficas atingidas por corridas de detritos; b) mapeamento e determinação da morfologia dos depósitos de corridas de detritos; e c) definição da magnitude. Os resultados mostraram que a magnitude potencial prevista para as bacias, de acordo com a sua classificação quanto à área de inundação, estão de acordo com os registros verificados a respeito do evento de 1967. Dessa forma, a metodologia pode ser aplicada no Brasil para determinação do potencial de magnitude de eventos de corridas de detritos, auxiliando nos trabalhos de prevenção e monitoramento de áreas suscetíveis.
\end{abstract}

Palavras chave: depósitos, corridas de massa, área de atingimento, Serra do Mar.

\section{Introdução}

Dada às suas características geológicas, geomorfológicas e climáticas, a Serra do Mar, localizada no litoral sul-sudeste do Brasil, é frequentemente atingida por movimentos de massa, em especial, escorregamentos e corridas de detritos. Tais processos, quando atingem áreas densamente ocupadas, causam danos sociais e econômicos de grandes proporções, como em 2011, na Região Serrana do Rio de Janeiro; em 2008, em Santa Catarina; e em 1967, em Caraguatatuba. As corridas de detritos se destacam dentre estes processos devido ao seu raio de alcance e ao seu potencial de transporte de diversos tipos de materiais (ex. árvores, lama e matacões), podendo transportar grandes blocos por longas distâncias, que podem afetar áreas menos declivosas, geralmente onde existem mais ocupações (COSTA, 1984; SELBY, 1993; GRAMANI, 2001, JAKOB, 2005, TAKAHASHI, 2007). No Brasil, as corridas, geralmente, estão associadas à dinâmica dos canais fluviais, sendo deflagradas pelo aporte de sedimentos oriundos de outros processos ou da remobilização de materiais da drenagem, o que contribui para o maior alcance e potencial destrutivo das mesmas. 


\section{OS DESAFIOS DA GEOGRAFIA FÍSICA NA FRONTEIRA DO CONHECIMENTO \\ Instituto de Geociências - Unicamp \\ Campinas - SP \\ 28 de Junho à 02 de Julho de 2017}

Diversos autores utilizam diferentes metodologias para a determinação do potencial de ocorrência e magnitude dos eventos, desde características gerais de deflagração, como ângulo das encostas e índice pluviométrico, até as características especificas de cada bacia hidrográfica atingida, como densidade de drenagem, índice de circularidade e índice de Melton (THUNDER CONSULTANTS LTD, 1983; COSTA, 1984; JAKOB, 1996; DE SCALLY et al. 2001; JAKOB, 2005; KONAVEN e SLYMAKER, 2008; DIAS et al., 2016). A proposta de Jakob (2005), por exemplo, leva em consideração três fatores para classificação da magnitude dos eventos de corridas de detritos: volume total transportado $\left(\mathrm{m}^{3}\right)$, pico de vazão $\left(\mathrm{m}^{3} / \mathrm{s}\right)$ e área de inundada $\left(\mathrm{m}^{2}\right)$, estipulando danos potenciais para cada nível estabelecido, que variam conforme a criticidade dos fatores. Conforme o exposto, o objetivo desta pesquisa foi determinar a magnitude de corridas de detritos em bacias hidrográficas em Caraguatatuba/SP considerando-se o fator "área inundada" na avaliação.

\section{2. Área de estudo}

O município de Caraguatatuba está localizado no litoral norte do Estado de São Paulo, na porção sudeste da Serra do Mar e se caracteriza, principalmente, pela proximidade com a escarpa da Serra do Mar e pelo clima tropical úmido, com predomínio de altos índices pluviométricos nos meses de dezembro a março. No verão de 1966-1967, o município foi atingido por elevado volume de chuvas, com um total de $946 \mathrm{~mm}$ no mês de março, chegando a um estado crítico nos dias 17 e 18, com 586 mm/48 h, deflagrando corridas de detritos e escorregamentos (Figura 1) (CRUZ, 1974). Os materiais mobilizados alcançaram área urbana do município (planície), deixando 120 mortos, 400 casas destruídas e danos a estrada de acesso ao município. Estima-se que cerca de 2 milhões de toneladas de materiais foram mobilizados (PETRI E SUGUIO, 1971). 


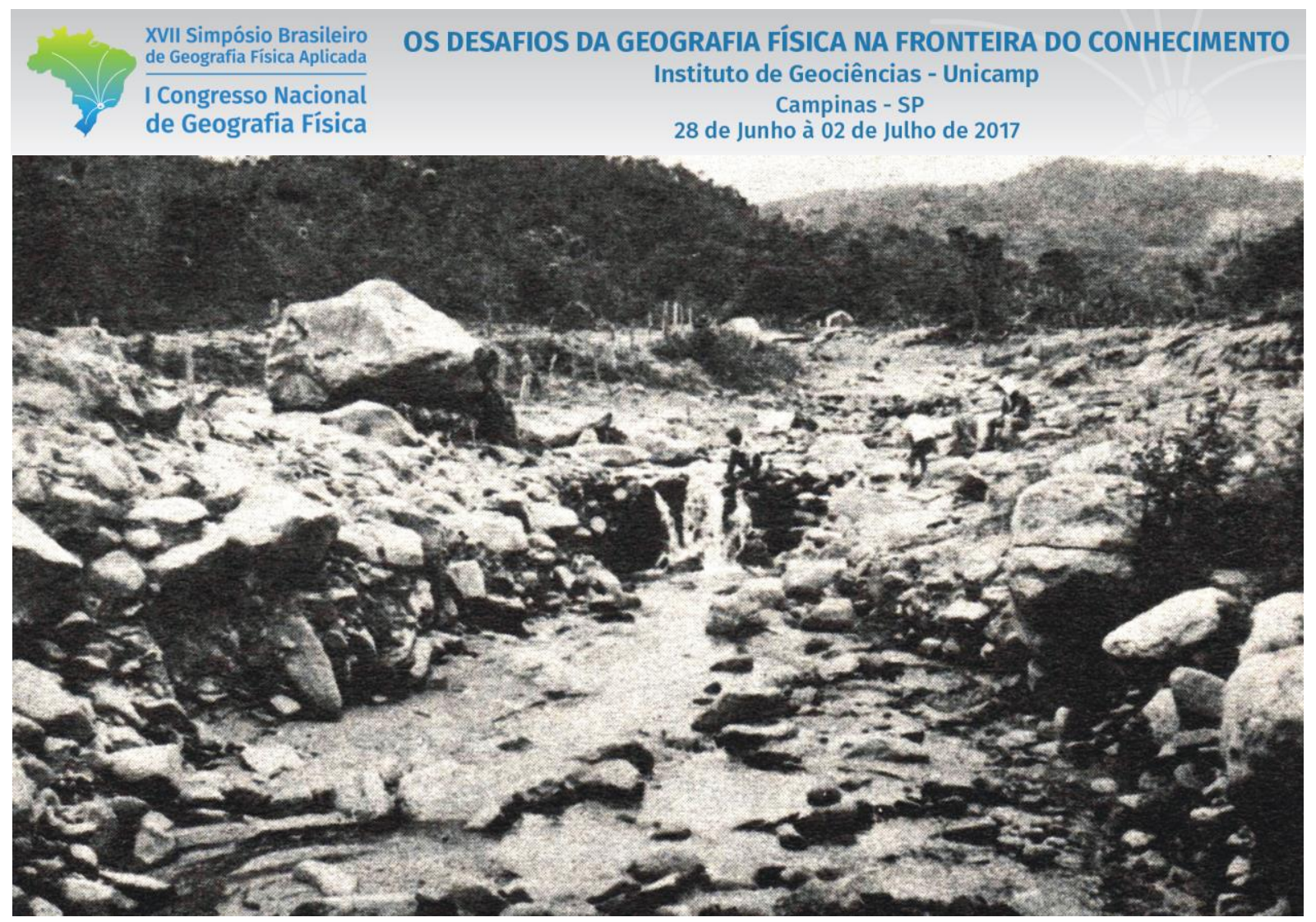

Figura 1: Corridas de detritos ocorridas em 1967, em Caraguatatuba/SP. Fonte: Arquivo Público de Caraguatatuba.

\section{Materiais e Métodos}

\subsection{Seleção de bacias}

Foram selecionadas quatro bacias hidrográficas com ocorrência de corridas de detritos de grande intensidade, evidenciada pela presença de depósitos: as bacias Pau d'alho (1), Ribeirão da Aldeia (2), Santo Antônio (3) e Guaxinduba (4) (Figura 2). As bacias foram selecionadas a partir de trabalhos de campo realizados no município de Caraguatatuba e com base nas informações de Cruz (1974) a respeito dos depósitos do evento de 1967. 


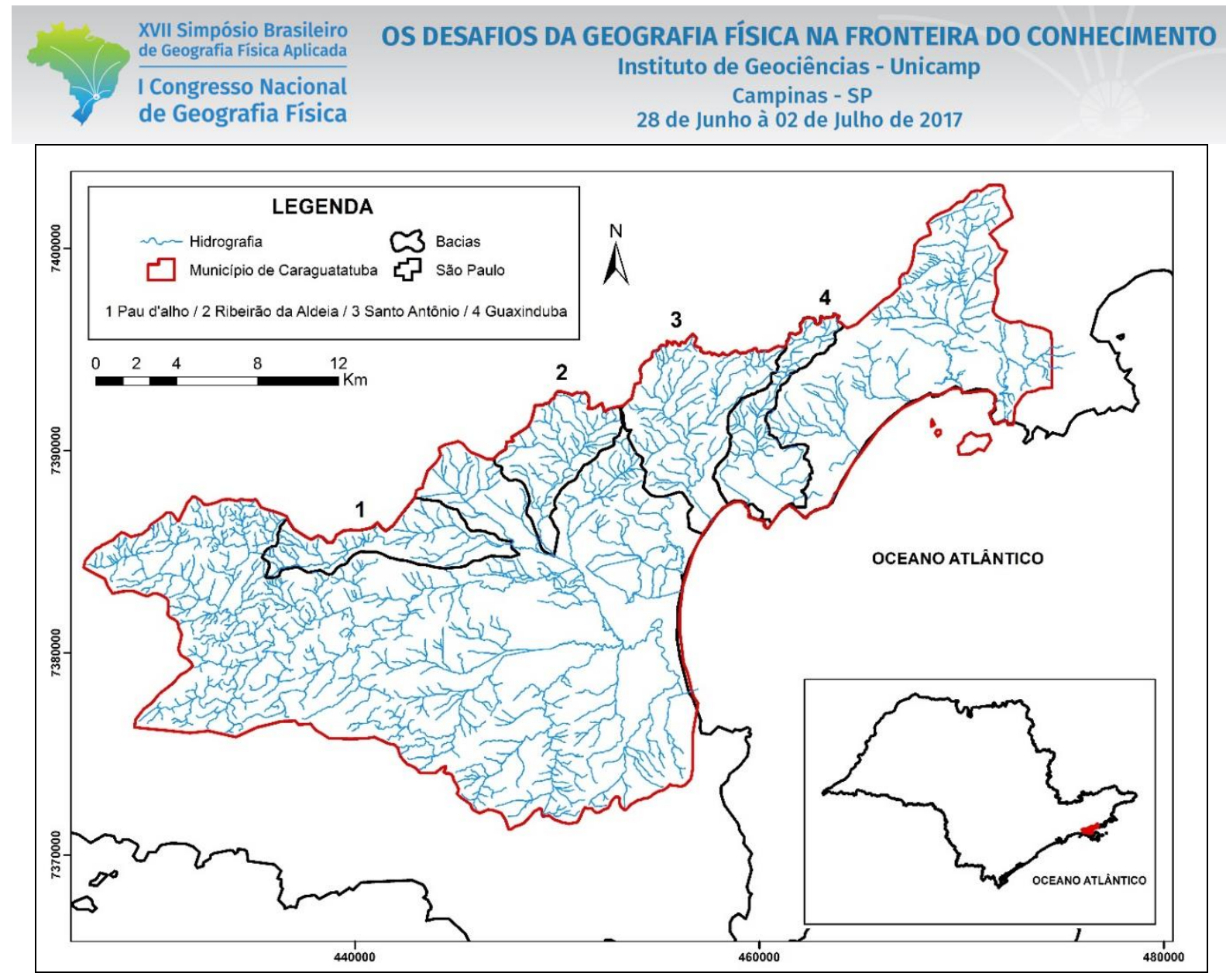

Figura 2: Localização das bacias selecionadas para análise em Caraguatatuba, litoral norte de São Paulo.

\subsection{Mapeamento e morfologia dos depósitos de corridas de detritos}

A identificação dos depósitos das corridas de detritos foi feita por meio de trabalhos de campo e da digitalização e interpretação do mapa elaborado por Cruz (1974) após o evento de 1967. Para classificação dos depósitos, foi utilizado o mesmo método de classificação dos depósitos utilizado por Dias et al. (2016), baseada em Stoffel (2010). Este método tem como base o mapeamento do tamanho dos blocos em campo (Figura 3). Também foi elaborada uma ficha de classificação dos depósitos para aplicação em campo, na qual são identificadas as características dos depósitos (presença de imbricamento, inversão granulométrica, etc.), o tamanho dos blocos (pequeno, médio, grande ou muito grande) e demais informações (croqui, outras características, etc.). 


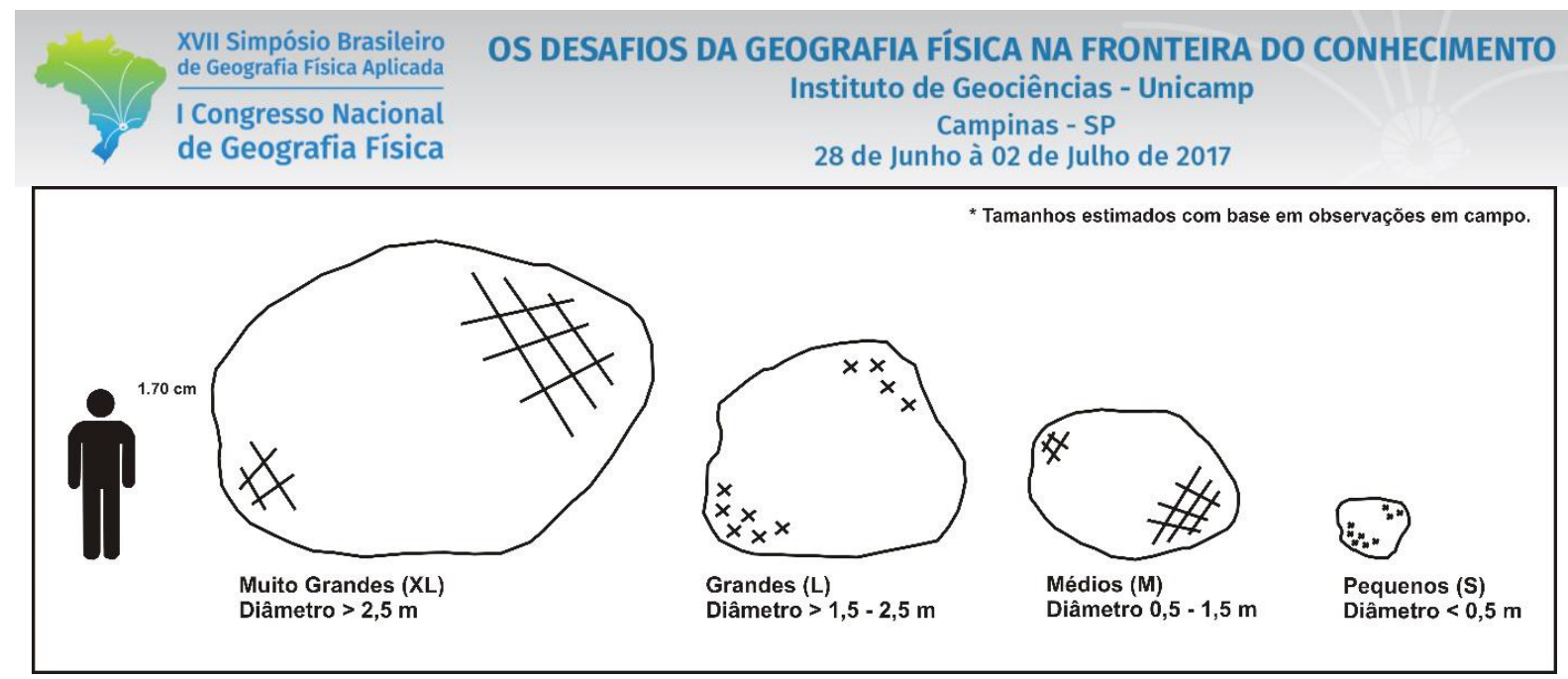

Figura 3: Classificação dos depósitos em quatro categorias: S, M, L e XL.

\subsection{Definição da magnitude}

Para definição da magnitude, foi utilizado o método proposto por Jakob (2005). O autor propôs uma classificação das consequências potenciais associadas às corridas a partir da avaliação do volume total mobilizado, pico máximo de vazão e área de inundação (Tabela 1). Tendo em vista que se trata de uma análise de um evento ocorrido há 50 anos e que dados precisos a respeito do volume total mobilizado e pico máximo de vazão são imprecisos ou até mesmo inexistentes, optou-se por usar o critério de área inundada $\left(\mathrm{m}^{2}\right)$, onde é levado em consideração o alcance total da corrida de detritos na bacia, ou seja, a área total inundada ou atingida (JAKOB, 2005). Para a sua determinação, além de trabalhos de campo para identificação de depósitos do processo, foram utilizados os mapeamentos de áreas atingidas por movimentos de massa em 1967 de Cruz (1990), e a carta geomorfológica da região de Caraguatatuba, também de Cruz (1974), sobretudo para as bacias Guaxinduba, Santo Antônio e Pau d' alho. Para a bacia do Ribeirão da Aldeia. Devido a indisponibilidade de mapeamentos pretéritos, a determinação do alcance foi feita majoritariamente por meio de trabalhos de campo. 
Tabela 1: Metodologia de classificação de magnitude de corridas de detritos (modificado de Jakob, 2005).

\begin{tabular}{|c|c|c|c|c|}
\hline \multicolumn{5}{|c|}{ CLASSIFICAÇÃO DE MAGNITUDE DE CORRIDAS DE DETRITOS } \\
\hline Nível & Volume $\left(\mathbf{m}^{3}\right)$ & $\begin{array}{c}\text { Pico de Vazão } \\
\left(\mathbf{m}^{3} / \mathbf{s}\right)^{*}\end{array}$ & $\underset{\left(\mathbf{m}^{2}\right)^{*}}{\text { Área inundada }}$ & Consequências Potenciais \\
\hline 1 & $<10^{2}$ & $<5$ & $<4 \times 10^{2}$ & $\begin{array}{l}\text { Dano muito localizado em pequenas } \\
\text { construções. }\end{array}$ \\
\hline 2 & $10^{2}-10^{3}$ & $5-30$ & $4 \times 10^{2}-2 \times 10^{3}$ & $\begin{array}{l}\text { Pode enterrar/arrastar carros, destruir } \\
\text { pequenas construções de madeira, derrubar } \\
\text { árvores, bloquear dutos e descarrilar trens. }\end{array}$ \\
\hline 3 & $10^{3}-10^{4}$ & $30-200$ & $2 \times 10^{3}-9 \times 10^{3}$ & $\begin{array}{l}\text { Pode destruir grandes construções, destruir } \\
\text { pontes de concreto, bloquear ou danificar } \\
\text { estradas e dutos. }\end{array}$ \\
\hline 4 & $10^{4}-10^{5}$ & $200-1.500$ & $9 \times 10^{3}-4 \times 10^{4}$ & $\begin{array}{l}\text { Pode destruir partes de um vilarejo, destruir } \\
\text { parte de infraestruturas, pontes e bloquear } \\
\text { canais. }\end{array}$ \\
\hline 5 & $10^{5}-10^{6}$ & $1.500-12.000$ & $4 \times 10^{4}-2 \times 10^{5}$ & $\begin{array}{l}\text { Pode destruir partes de uma cidade, destruir } \\
\text { florestas de } 2 \mathrm{~km}^{2} \text { de área, bloquear canais e } \\
\text { pequenos rios. }\end{array}$ \\
\hline 6 & $10^{6}-10^{7}$ & N/A & $>2 \times 10^{5}$ & $\begin{array}{l}\text { Pode destruir partes de uma cidade, } \\
\text { entulhar vales ou depósitos de mais de } 10 \\
\mathrm{~km}^{2} \text { de tamanho, criar barragens de } \\
\text { materiais em rios (bloqueio). }\end{array}$ \\
\hline 7 & $10^{7}-10^{8}$ & N/A & N/A & $\begin{array}{l}\text { Pode destruir partes de uma cidade, obstruir } \\
\text { vales, com depósitos de mais de } 10 \mathrm{~km}^{2} \mathrm{em} \\
\text { tamanho e criar barragens de materiais em } \\
\text { rios (bloqueio). }\end{array}$ \\
\hline 8 & $10^{8}-10^{9}$ & N/A & N/A & $\begin{array}{l}\text { Pode destruir cidades e inundar grandes } \\
\text { vales, com depósitos maiores de } 100 \mathrm{~km}^{2} \mathrm{de} \\
\text { tamanho, criar barragens de materiais em } \\
\text { rios (bloqueio). }\end{array}$ \\
\hline 9 & $10^{9}-10^{10}$ & N/A & N/A & $\begin{array}{l}\text { Destruição vasta e completa por mais de } \\
\text { centenas de } \mathrm{km}^{2} \text {. }\end{array}$ \\
\hline 10 & $>10^{10}$ & N/A & N/A & $\begin{array}{l}\text { Destruição vasta e completa por mais de } \\
\text { centenas de } \mathrm{km}^{2} \text {. }\end{array}$ \\
\hline
\end{tabular}

*Dados específicos para corridas de detritos com blocos (não vulcânicas). N/A: sem observação destas magnitudes para corridas de detritos com grandes blocos.

\section{Resultados e Discussões}

Todas as bacias apresentaram depósitos de corridas de detritos compostos por blocos de tamanhos pequenos a muito grandes, com destaque para as bacias dos rios Santo Antônio e Guaxinduba, que apresentaram a maior quantidade de blocos de tamanho "muito grandes" (Figuras 4A e 4B), comparado às demais bacias. Os resultados demonstram que as corridas de detritos ocorridas em Caraguatatuba possuem elevado poder destrutivo, representado pelo tamanho dos blocos transportados. Tais materiais, 


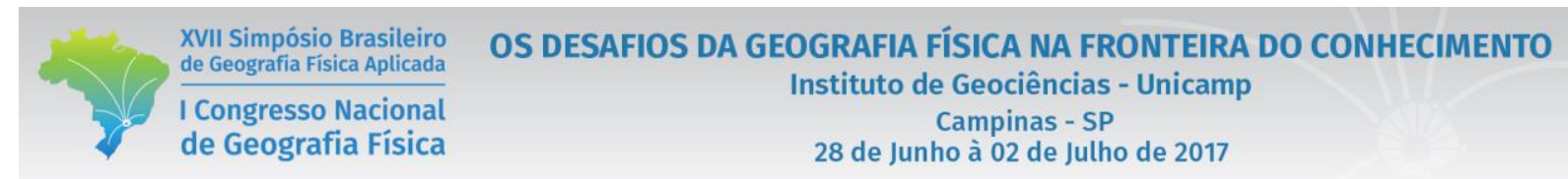

quando envoltos no fluxo, podem ser transportados por grandes distâncias, apesar de seu peso e tamanho, dado aos mecanismos atuantes nas corridas de detritos (JOHNSON, 1970; COSTA, 1984), podendo atingir as porções mais baixas do relevo e causar danos às infraestruturas urbanas.

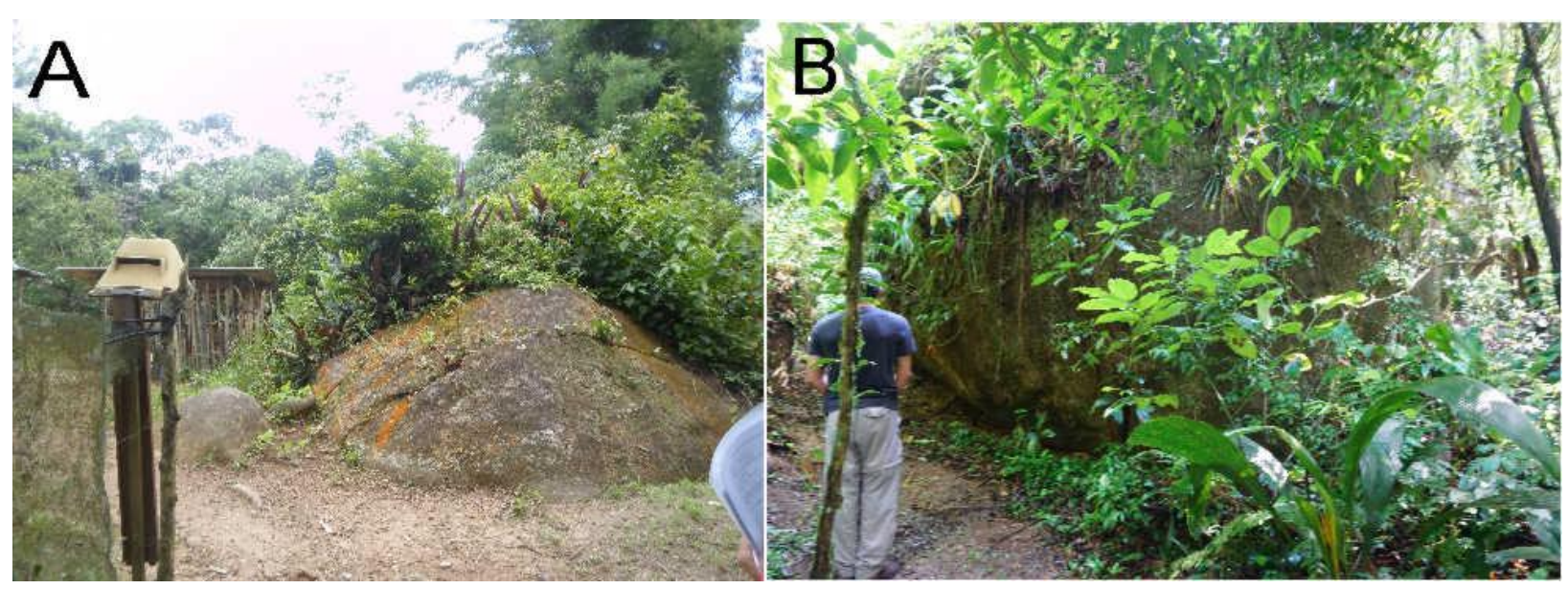

Figura 4: (A) Bloco de tamanho "muito grande" localizado na bacia do Guaxinduba e (B) na Bacia do Rio Santo Antônio.

Com relação à determinação da magnitude a partir da área de atingimento, as bacias se diferenciaram quanto ao nível de magnitude. As bacias dos rios Santo Antônio, Guaxinduba e Pau d'alho apresentaram as maiores magnitudes, Níveis 3, 2 e 2, respectivamente, de acordo com a classificação de Jakob (2005) (Figura 5). Já a bacia do Ribeirão da Aldeia apresentou magnitude de Nível 1. Tal resultado corrobora os dados referentes ao evento de 1967 apresentados por Cruz (1974) e verificado a partir de registros do evento, disponibilizados pelo arquivo público do município, sobretudo com relação aos danos causados.

A bacia do rio Santo Antônio foi classificada com a maior magnitude. Segundo a classificação de Jakob (2005), nos danos potencias previstos para o Nível 3 as corridas "podem destruir grandes construções, destruir pontes de concreto, bloquear ou danificar estradas e dutos". Danos estes que estão de acordo com os registros da ocorrência nas bacias, localizada na porção central do município (Figura 6A e B).

A bacia do rio Guaxinduba foi classificada com magnitude de Nível 2, que segundo Jakob (2005), "podem enterrar/arrastar carros, destruir pequenas construções de madeira, derrubar árvores, bloquear dutos e descarrilar trens". A área de inundação do rio Guaxinduba, em comparação à Santo Antônio, foi menor e mais concentrada no centro da bacia, não ocorrendo um espraiamento do fluxo como na Santo Antônio (Figura 5). 


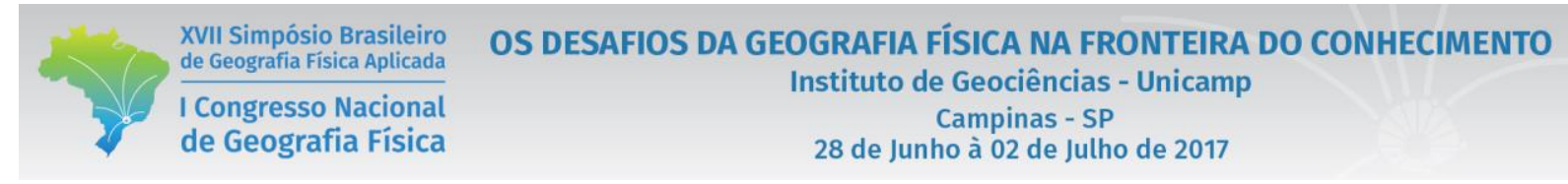

Ressalta-se, também, que na década de 1960 a bacia do rio Guaxinduba não era tão densamente ocupada como é atualmente, portanto não há registros de danos como há para a Santo Antônio. No entanto, observa-se que a classificação prevê danos menores, considerando o atingimento em uma área menor. Dessa forma, as consequências potenciais previstas também estão de acordo com relação à essa bacia.

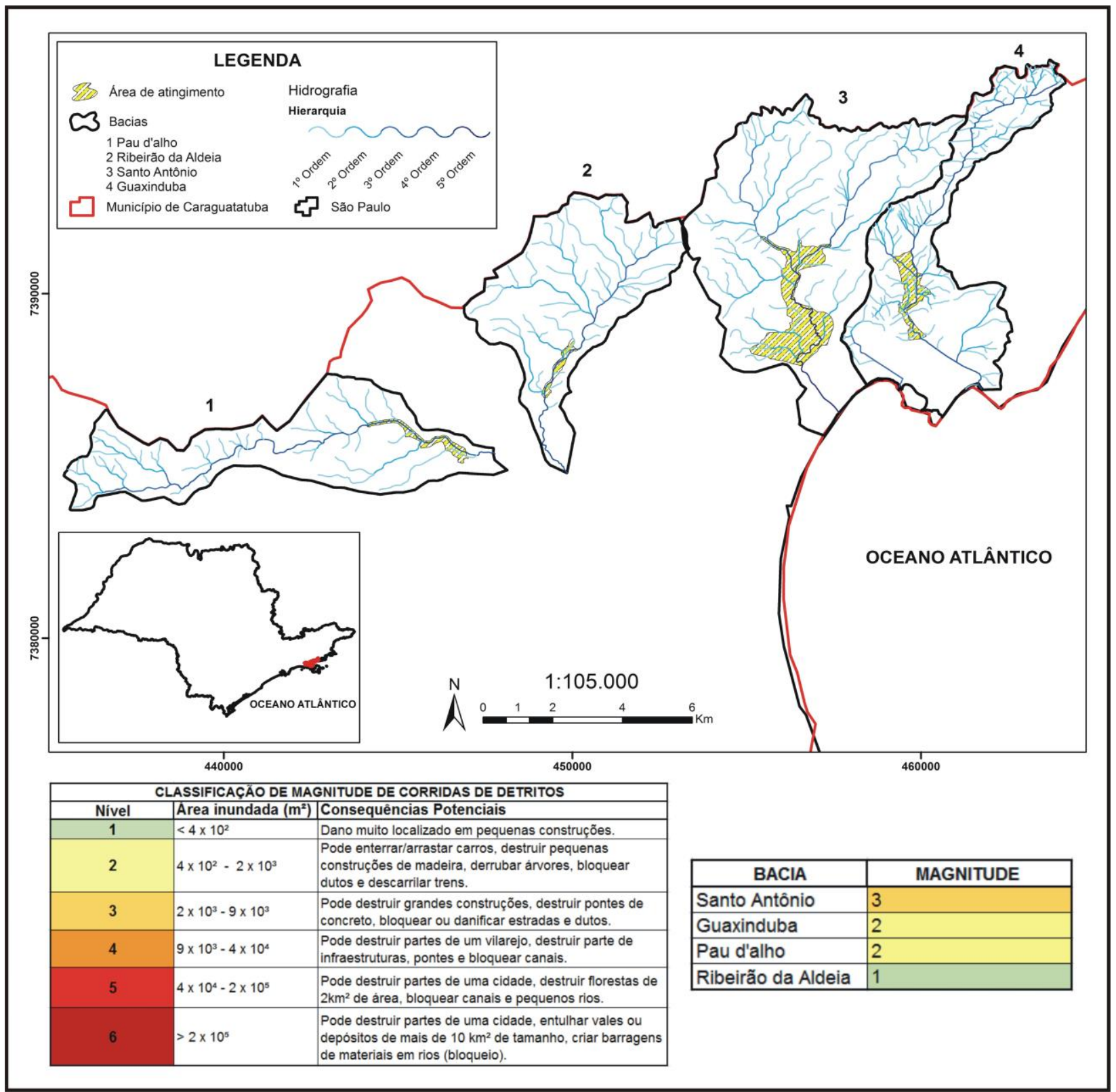

Figura 5: Classificação da magnitude segundo metodologia proposta por Jakob (2005). 

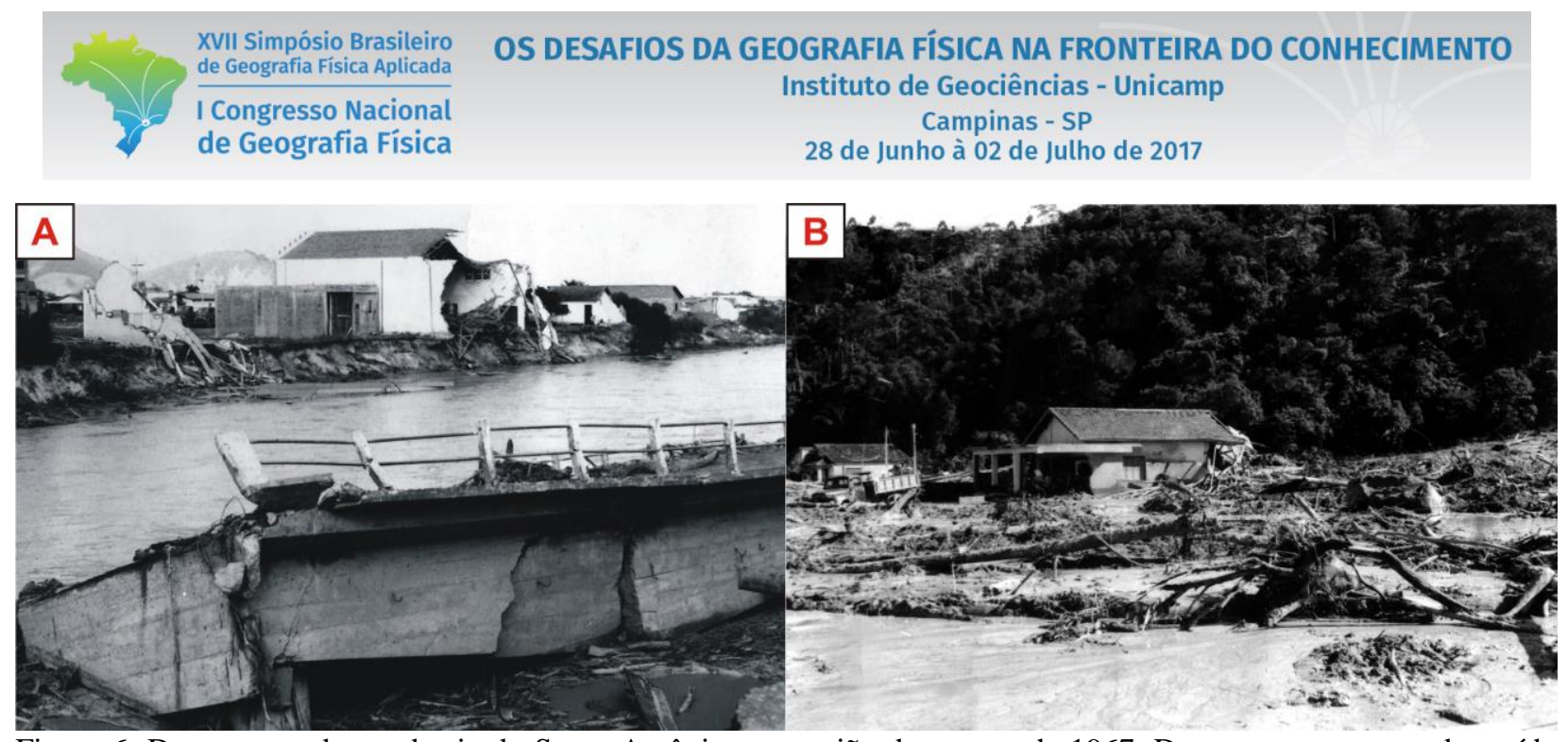

Figura 6: Danos causados na bacia do Santo Antônio na ocasião do evento de 1967. Destaque para ponte destruída (A) e moradia também com danos devido à ocorrência de corridas de detritos (B). Fonte: Arquivo Público de Caraguatatuba.

A bacia Pau d'alho, também classificada com Nível 2, apresentou magnitude intermediária entre a bacia Guaxinduba e a bacia Ribeirão da Aldeia, uma vez que a área de inundação verificada foi menor do que a verificada na bacia Guaxinduba e maior do que a verificada na bacia Santo Antônio (Figura 5). Trata-se de uma área sem ocupações, estando localizada em área privada, na fazenda Serra Mar, o que favoreceu a conservação dos depósitos das corridas de detritos, preservando feições características, como a inversão granulométrica dos blocos, quando os materiais mais grosseiros ficam suspensos sobre os materiais mais finos (Figura 7A).

Por fim, a bacia Ribeirão da Aldeia foi classificada com Nível 1, com seguinte potencial destrutivo previsto "Dano muito localizado em pequenas construções" (JAKOB, 2005). O alcance das corridas nessas bacias foi bem localizado (Figura 5), apenas atingindo áreas e construções muito próximas ao canal principal. Na bacia do Ribeirão da Aldeia, cujo alcance foi determinando com base em trabalho de campo e na identificação dos depósitos na bacia, observou-se apenas uma construção antiga abandonada em uma área de deposição de blocos. Dessa forma, embora apresente depósitos compostos por blocos de tamanho muito grande, a magnitude do evento em si foi classificada no nível mais baixo devido à sua abrangência (Figura 7B). 


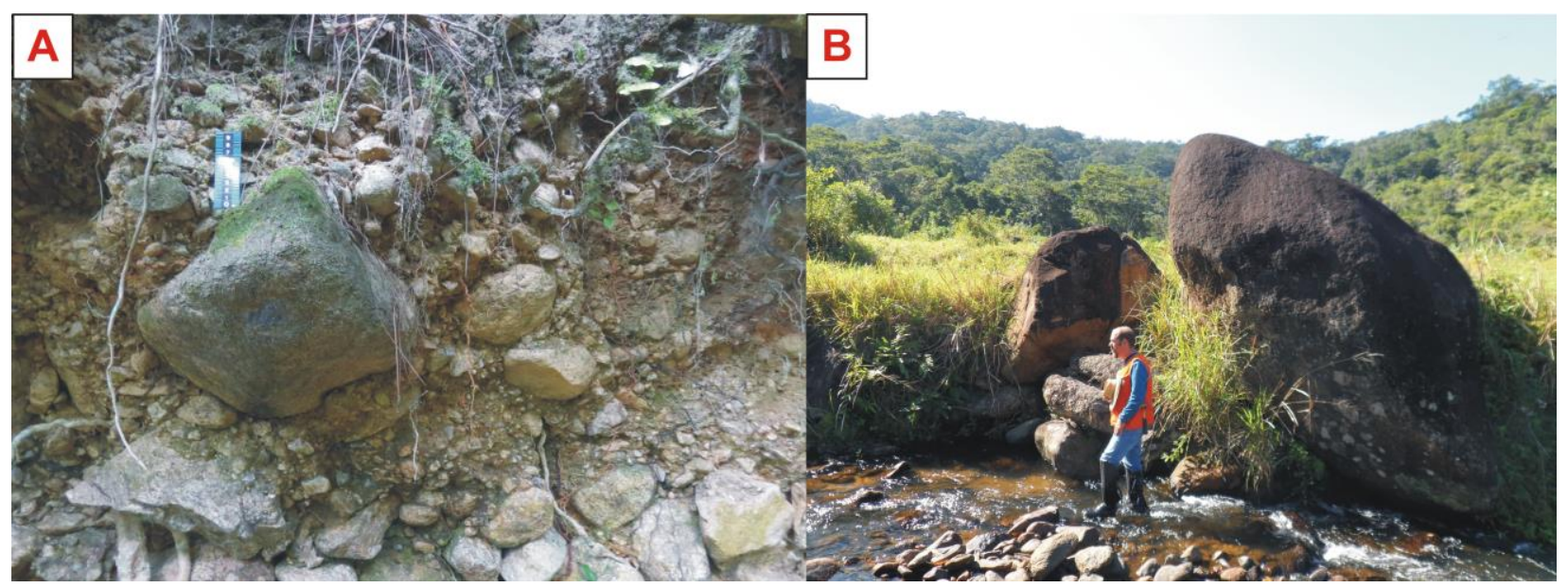

Figura 7: Depósitos de corridas de detritos localizados nas bacias Pau d'alho (A) e Ribeirão da Aldeia (B).

\section{Conclusão}

A determinação da magnitude em bacias hidrográficas, combinado à avaliação da morfologia dos depósitos, foi feita para algumas bacias mais atingidas pelo processo no evento de 1967, em Caraguatatuba/SP. Como resultado, obteve-se o mapa de área de atingimento para as bacias e respectiva classificação das mesmas quanto à magnitude. O mapeamento da magnitude combinado à área de atingimento e às características dos depósitos se mostrou eficiente, ficando os danos potenciais previstos para cada nível de acordo com a realidade.

Embora tratar-se de uma proposta visando, sobretudo, as ocorrências de corridas de detritos no hemisfério norte, que diferem quanto ao modo de deflagração das corridas no Brasil, os resultados desta pesquisa demonstraram que o método pode ser utilizado no Brasil para definição da magnitude dos eventos.

\section{Agradecimentos}

Os autores agradecem a Coordenação de Aperfeiçoamento de Pessoal de Nível Superior (CAPES) pelo apoio financeiro para a realização da pesquisa, ao Programa de Pós-Graduação em Geografia Física (PPGF) da Universidade de São Paulo, ao Instituto de Pesquisas Tecnológicas do Estado de São Paulo (IPT) e aos membros do Grupo de Pesquisa de Processos Morfodinâmicos (GPMorfo). 


\section{Bibliografia}

ARQUivo PÚBLICO DE CARAGUATATUBA. Catástrofe de 1967 no município de Caraguatatuba. Caraguatatuba, SP, 1967.

COSTA, J. E. Physical geomorphology of debris flows. In Costa, J. E., and Fleisher, J. P., eds., Developments and applications of geomorphology, New York: Springer-Verlag, 1984. p. 268-317.

CRUZ, O. A Serra do Mar e o litoral na área de Caraguatatuba - SP. Contribuição à geomorfologia litorânea tropical. Tese de Doutorado. IG - Série Teses e Monografias n 11, 1974. 181p.

CRUZ, O. Contribuição geomorfológica ao estudo de escarpas da Serra do Mar. Revista do IG 11, 1990. p. 920.

DE SCALLY, F., SLAYMAKER, O. e OWENS, I. Morphometric controls and basin response in the Cascade Mountains. Geografiska Annaler, 83 A (3), 2001. p. 117-130.

DIAS, V. C., VIEIRA, B. C., e GRAMANI, M. F. Parâmetros morfológicos e morfométricos como indicadores da magnitude das corridas de detritos na Serra do Mar Paulista. Confins [Online], 29 | 2016. URL: http://confins.revues.org/11444; DOI: 10.4000/confins.11444.

GRAMANI, M.F. (2001) Caracterização geológico-geotécnica das corridas de detritos ("debris flows") no Brasil e comparação com alguns casos internacionais. Dissertação (Mestrado) Escola Politécnica da Universidade de São Paulo, 372p.

JAKOB, M. Morphometric and geotechnical controls on debris flow frequency and magnitude in Southwestern British Columbia. Ph.D. Dissertation, University of British Columbia, 1996. 232p.

JAKOB, M. Debris-flow hazard analysis. In: Debris-flow hazards and related phenomena (Eds. Jakob, M. and Hungr, O.). Springer, 2005. p. 442-474.

JOHNSON, A. M. Physical Processes in Geology. A method for interpretation of natural phenomena intrusions in igneous rocks, fractures and folds, flow of debris and ice. Freeman, Cooper \& Company, San Francisco, Califórnia. 1970. 577p.

KONAVEN, D. J. e SLAYMAKER, O. The morphometric and stratigraphic framework for estimates of debris flow incidence in the North Cascades foothilss, Washington State, USA. Geomorphology 99, 2008. p. 224-245.

PETRI, S. E SUGUIO, K. Características granulométrica dos materiais de escorregamentos de Caraguatatuba, São Paulo, como subsídio para o estudo da sedimentação neocenozóica do Sudeste Brasileiro. $25^{\circ}$ Congr. Bras. Geol., Bol. Esp. São Paulo, nº 1, 1971. p. 199-200.

SELBY, M. J. Mass wasting of soils. In: Hillslope materials and processes. Second Edition. Oxford University Press, Oxford, 1993. p. 249-355.

STOFFEL, M. Magnitude-frequency relationships of debris Flow - A case study based on field survey and tree-ring records. Geomorphology, 116, 2010. p. 67-76.

TAKAHASHI, T. Debris Flow: mechanics, prediction and countermeasures. Taylor \& Francis Group, London, UK. 2007. 439p.

THUNDER CONSULTANTS LTD. Mitigation of debris flow hazard, Springs Creek fan, report to Morgan Stewart and Company Limited. Victoria, B. C. 1983. 